\title{
Assessing the Suitability of the Cold Bending Method in Fabricating Free-form Façade Panels
}

\author{
Jong Hom Ock* \\ Construction Management Engineering, Seoul National University of Science \& Technology, South Korea
}

Submission: January 24, 2018; Published: May 17, 2018

*Corresponding author: Jong Hom Ock, Construction Management Engineering, Seoul National University of Science \& Technology, South Korea, Email: ockjh@seoultech.ac.kr

\begin{abstract}
Free-form buildings are one of the latest unique trends in the construction industry worldwide. A number of projects have been undertaken in different parts of the world. These structures are hailed for their stunning aesthetics and jaw-dropping curvatures. However, the design, fabrication and installation of free-form façades is very difficult process as it requires unprecedented precision. Free-form façade construction could yield such distresses as towering costs, leakages and panel twisting if not well managed from early stages. The choice of a production method is paramount as it impacts on both the cost and the aesthetics of the structure. This study dwelled on the use of cold bending for fabrication of free-form façade panels. Design BIM data of a small free-form building in Korea and later mock-up panels was overlapped and compared with the As-built data of the panels obtained by laser scanning. The discrepancy in the panel data before and after construction was assessed and attributed to the method of panel fabrication used. It was then concluded that cold bending is suitable for fabrication of flat and single curvature metallic panels, but has limitations for double curvature panels depending on the degree of curvature and expertise of the fabricator.
\end{abstract}

Keywords: Free-form construction; Laser scanning; Cold bending; Overlapping comparison; Panelization; Mock-up panel fabrication

Abbreviations: BIM: Building Information Modelling; DP: Digital Project; LIDAR: Light Detection and Ranging; RADAR: Radio Detection and Ranging

\section{Introduction}

\section{Background and purpose}

Free-form design has increasingly gained popularity in the recent 'zero' decade [1]. This is mainly attributed to the increase in the use of computers to easily produce complex designs in a comparatively short period of time. A free-form building refers to 'all or portion of a building that is sloped, narrowed, deformed, or consisting of irregular curves instead of quadrangle' [2].

With the introduction and advancement of digital design and Building Information Modelling (BIM), the plight of realization of free-form buildings has become increasingly easier. The computer applications have enabled world renowned designers like Zaha Hadid and Frank Ghery, who have come up with the curvy, slender, wriggly landmarks of the modern age.

The most difficult process in constructing free-form buildings is to form and fabricate the façade. To incarnate the facade, the complex geometric shapes of the façade should be divided into the panels with the forms and sizes that can be manufactured and fabricated efficiently. Optimization of façade panels is carried out during design so as to derive the most cost effective and aesthetic panel curvatures.
There are several methods of forming and fabricating freeform panels used all over the world. The most common ones include hot bending, cold bending, hydroforming, die forming and others. The choice of the method to be used depends on the cost, curvature of the panels, and manufacturing speed. This study focuses on the cold bending method of metal sheet processing and its application in the forming and fabrication of free form panels. With cold bending, curved surfaces are produced by forcefully bending and fixing flat, thick, sheet metal pieces along the curved surface on site [3].

One of the drawbacks of cold bending on metallic panels is the visible gaps at the joints of each panel which distorts the beauty of the façade. However, not so much information has been published which thoroughly scrutinizes the application of cold bending of metal panels on free-form buildings. This study intends to assess the suitability of the cold bending method on free-form buildings by pragmatically analyzing the difference between the as-built and the as-planned façade parameters.

\section{Scope and method}

The façade panel materials of free-form buildings include glass, aluminum, steel, Glass Fiber Reinforced Concrete (GFRC) 
and many more, among which aluminum is the most frequently used. This study focuses on the design, fabrication and inspection of aluminum and GFRC panels to create free-form facades. The followings are research processes to meet the research objective:

a) Through literature review, the theoretical drawbacks of the cold bending method were investigated. Two freeform building projects whose panels were fabricated by cold bending were identified for practically reviewing real-world problems.

b) Haewoojae, another free-form building fabricated with the cold-bending method in Korea, was selected to measure the difference of the as-built from the as-planned. As-built results of Haewoojae were extracted through 3D laser scanning technology, overlapped with the as-planned data of the facility, and compared to gauge the magnitude of deviation with the as-planned data.

c) In order to make the findings of the comparison more reliable and generally acceptable, mock-up aluminum and GFRC panels of various curvatures were fabricated under the supervision of a group of 4 free-form fabrication and installation experts.

d) The as-designed and as-manufactured BIM data of the mock-up panels were also compared with the overlapping method and the causes of the deviations analyzed. The comparison results were used to establish the circumstances under which cold bending is applicable as a method of freeform panel fabrication.

\section{Literature Review}

\section{Definitions}

Free-form shapes play an important role in contemporary architecture. To form the curved facade, the facades of the freeform buildings should be divided into the shape and size that can allow production and fabrication, which is called panelization [4]. Panelization methods change depending on the shape of free-form surfaces, designer's intention, and panel creation algorithm. However they can broadly be classified depending on the shape they take up, for example, triangular, quadrangular, or polygonal.

Free-form panels can be majorly classified into three categories according to curvature. Panels with curvature less than $5 \mathrm{~mm}$ are termed as flat panels, those with curvature bending in one direction are termed as single curvature panels, while those with curvature bending in two directions are classified as double curvature panels [5].

At the design stage of a free-form building, designers create very complex $3 \mathrm{D}$ building shapes that reflect their design inspiration. The initial panel models to embody these shapes consist of free curves with curvatures that change in many ways, causing difficulty in production and fabrication. Designers need to adjust the initial panel models to secure constructability at reasonable cost while maintaining the aesthetic quality of freeform shapes and surface smoothness. This process is called panel optimization [6]. The bigger the curvature, the more difficult it is for the panel to be constructed and thus a higher cost.

\section{Panel forming methods}

There are various methods that can be used in forming metal free-form panels. Cutting, roller bending, and pressing are methods generally used to fabricate curved surfaces. Special forming methods such as stretch forming, die casting, single point forming, die-less forming, hydro-forming, multi-point forming, and explosive forming have also been used [3].

Various processing methods are used together according to the required shapes of panels. Lee and Kim [3] carried out the case study of mass customization of double curved metal façade panels using a new hybrid sheet metal processing technique. The authors, who were façade consultants on the Dongdaemun Design Park, which was the first free-form building built in Korea, undertook the study because the available panel manufacturing techniques at the time, including cold bending, were not appropriate for the very curvy building designed by Zaha Hadid.

\section{Cold bending}

Metal bending refers to an operation in which a portion of a metal is flexed along a line or curve until a bend is obtained. While metals can either be bent at room temperature or with application of heat,cold bending is a metal bending method by forcefully bending and fixing flat, thick, sheet metal pieces along the curved surface on site at room temperature [7].

The biggest drawback of metal bending is spring-back, or back returning force within the metal. A metal always tends to go back to its original shape after the deforming force has been withdrawn. Spring-back is 'the amount of elastic distortion a material has to go through before it becomes permanently deformed, or formed [7]. Figure 1 shows spring-back of a metal flange.

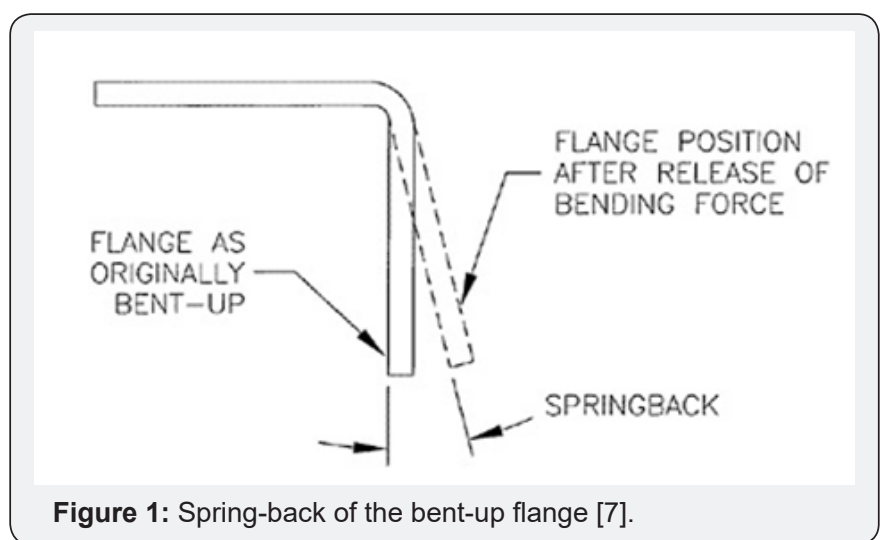

There are several factors that influence the amount of springback of a metal as follows: 


\section{Civil Engineering Research Journal}

a) Ductility of material: Spring-back in more ductile materials is less than in rigid or less ductile materials. Therefore metals such as aluminum although fairly ductile with a ductility of 0.65 [8] is bound to experience a certain amount of spring-back when bent.

b) Size of metal segment: Larger area segments tend to have more spring-back than smaller area segments. Flatness of the surface is also difficult to produce due to the 'oilcan effect'. This is when a surface snaps back and forth like an oil can when pressed upon by hand. It can be corrected through a costly procedure of submitting the surface to pressures excessive of its modulus of elasticity using hydraulic press.

c) Bending angle: The sharper the angle the lesser the spring-back. Obtuse angles are more prone to spring-back than acute angles. Therefore since the curvature of the freeform panels is not acutely sharp, even for double curved panels, the panels formed using cold bending method are bound to deviate from their original curvatures due to spring-back.

d) Bend radius: The bend radius (curvature) has a profound effect on the success of the bending operation. The radius depends majorly on the material thickness and material hardness.

This study identified two free-form building projects where cold bending was applied. While the projects demonstrated their aesthetic features with curved facades, some drawbacks were identified due to spring-back of a metal.

\section{J Museum}

Designed by a France studio XTU architects, Jmuseum is a meandering free-form structure developed by the regional Korean government as a part of the efforts to preserve the Asian History and promote tourism. The double perforated walls of the $6,700 \mathrm{~m}^{2}$ building, enveloped with rectangular stainless steel panels, references the pattern of a reptile skin that reflects the peripheral scenery [9].

Figure 2a shows exterior view of the stainless steel envelope of the museum. However, on some parts of the envelops, the panel joints were observed to be staggering in an irregular pattern, insinuating a problem in the fabrication or cold-bending method as shown in Figure $2 \mathrm{~b}$.

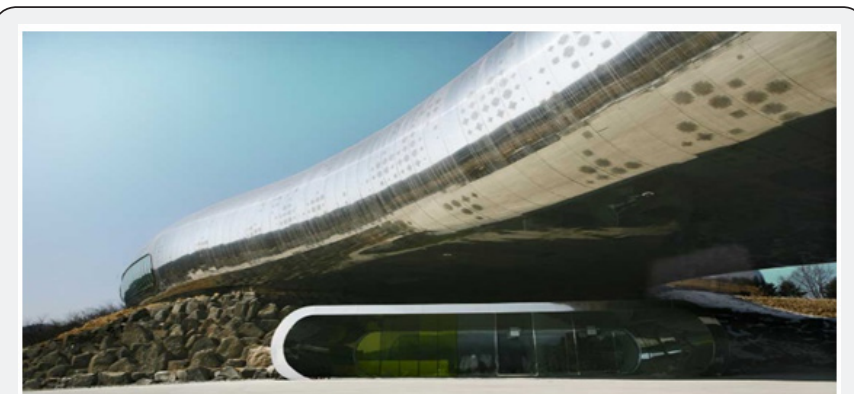

Figure 2 (a): Pictures of $\mathrm{J}$ Museum. Exterior view of $\mathrm{J}$ museum [9].

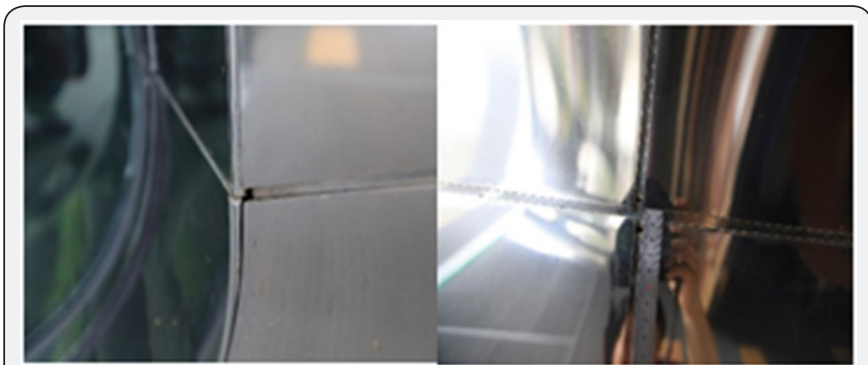

Figure 2 (b): Pictures of J Museum. Defective Fabrication Examples [15].

\section{Experience Music Project (EMP)}

This is a contemporary popular culture museum located in Seattle Washington, USA [10]. The 13,000 2 museum designed by Frank Gehry consists of a sheet metal façade that was fabricated using cold bending methodology. The roof is made up of 21 thousand panels of stainless steel with shades of purple, silver and gold, aluminum and painted red and blue. However, as shown in Figure 3, the tendency to spring-back and the gaps created around the panel joints due to cold bending are clearly visible.

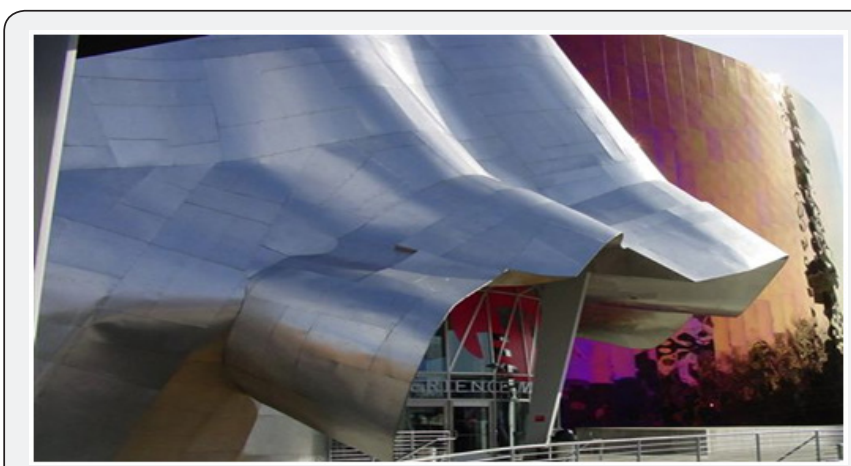

Figure 3: Façade of Experience Music Project [10].

\section{Case Study}

This research utilized Haewoojae as a specimen for measuring the cold-bending problem. Haewoojae is a toilet museum built in 2007 in Korea. Shown in Figure 4, the facility is two-story having $418 \mathrm{~m}^{2}$ gross floor area, of which glass and aluminum panel façade consists of free-form panels of various curvatures [11].

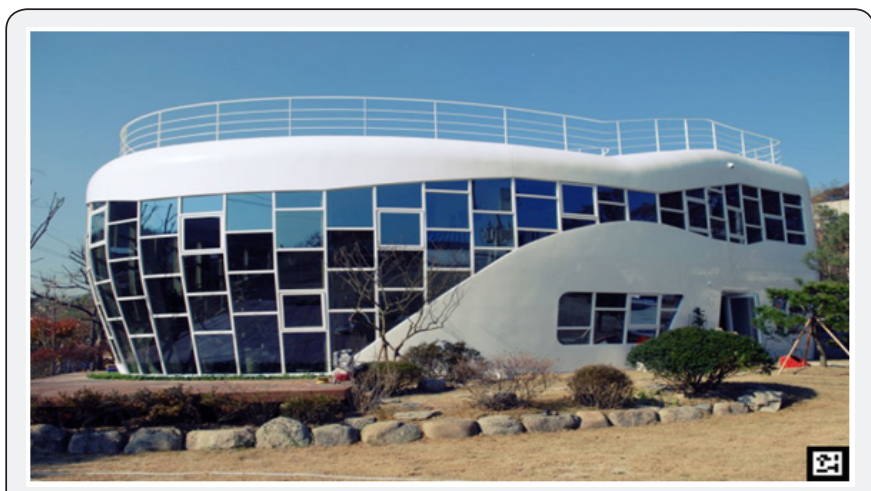

Figure 4: Haewoojae [11] 


\section{Civil Engineering Research Journal}

\section{As planned data}

Figure 5 represents Haewoojae modeling results and process with Digital Project (DP). DP is a commercial software produced by Gehry Technology in 1992 on the basis of CATIA program.
Panelization was performed with rectangular and triangular panel shapes. The basic panel size used in the modeling was $1 \mathrm{~m}$ $\mathrm{x} 1 \mathrm{~m}$ and smaller ones were applied depending on the building curvatures configuration.
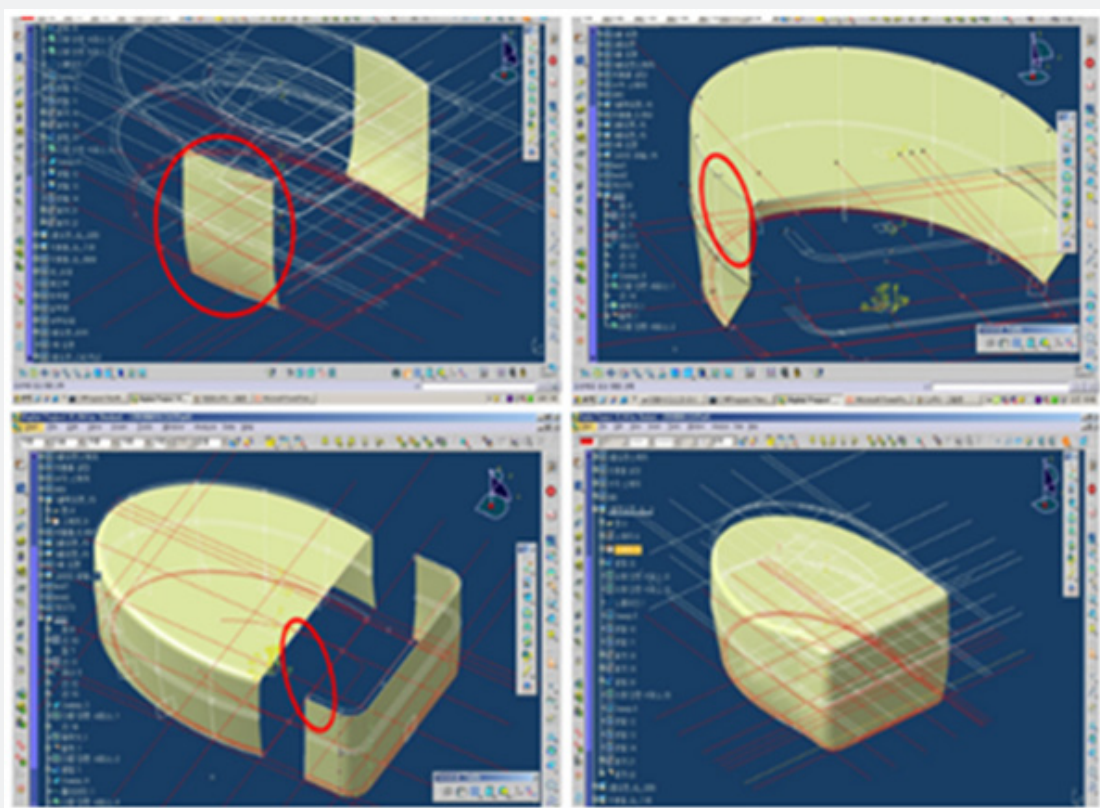

Figure 5: As-Planned Modeling Process with Digital Project.

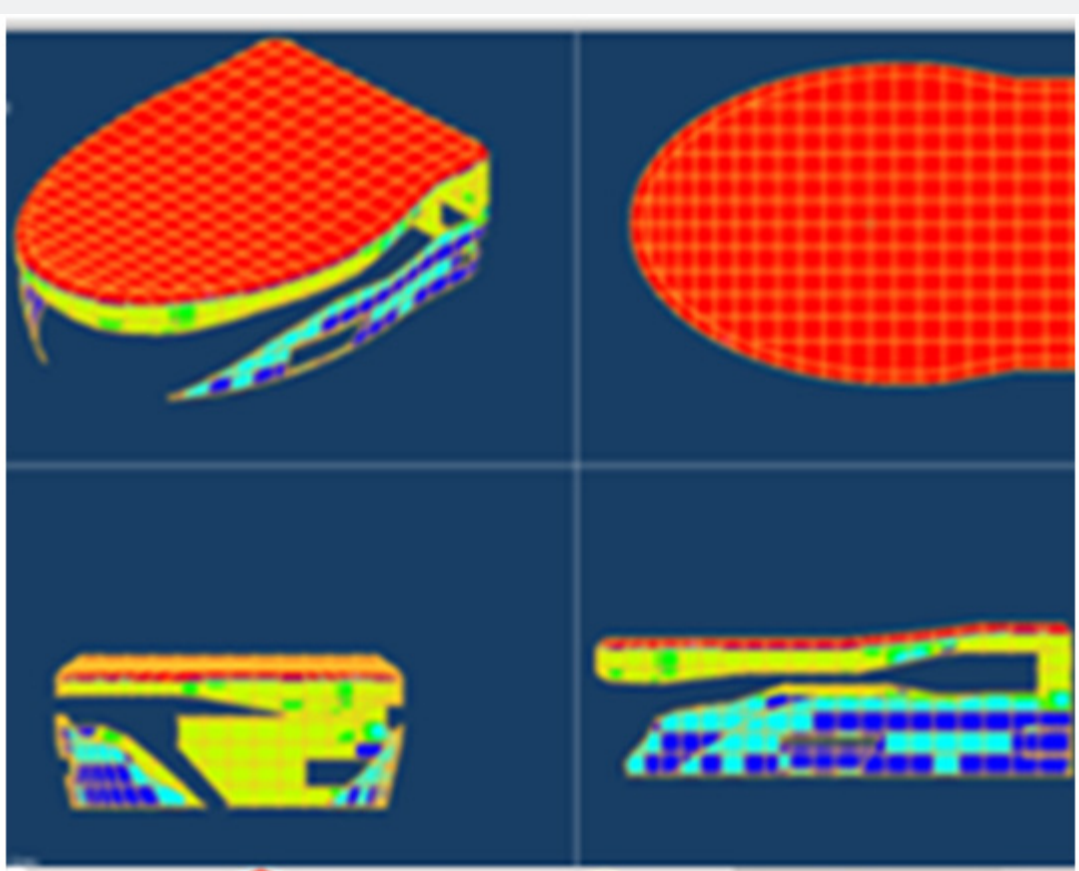

Figure 6: Location of the Different Panel Types in Haewoojae.

A total of 533 panels along with 4 different panel types were identified through panelization: 262 flat panels, 204 single curvature panels with curvature less than $200 \mathrm{~mm}, 63$ single curvature panels with curvature more than $200 \mathrm{~mm}$, and 24 double curvature panels. Figure 6 demonstrates the panel types with different colors: red - flat panels; blue -single curvature less than $200 \mathrm{~mm}$; yellow -single curvature more than $200 \mathrm{~mm}$, and green -double curvature panels.

Panels with large curvature were seen in the 1st and 2nd floor joints, the 2 nd floor and roof joints, and the front and rear curved areas of the building. While it was desirable to produce 


\section{Civil Engineering Research Journal}

the large curvatures panels with computer-based digital production process for example using CNC machine to secure after-fabrication aesthetic quality, all of the panels were formed and fabricated with the cold bending method in the job site by the handymen using 2D drawings of the facility.

\section{As-built data comparison}

3D laser scanning technology was used to obtain as-built data of Haewoojae. 3D laser scanning is a relatively new technology that uses light detection and ranging (LIDAR) to extract 3D accurate representations of objects [12]. It is very similar to radio detection and ranging (RADAR) but the laser technology utilizes light to measure range or distance instead of radio.

Since the initial data generated by 3D laser scanning technology has only the location information represented with point clouds, the volume elements of a panel is not to be obtained automatically so that parametric conversion of the data was impossible. Just like getting the as-planned data of Haewoojae with DP, this study utilized DP to produce the surface outlines of the scanned facility data and converted those to BIM parametric data for comparison.
There are several previous research that adapted the 3D scanning technology in the construction industry including Su et al [12], Shin and Huang [13], and Park et al. [14]. The research mostly focused on the procedures and manipulation techniques of capturing current data of buildings, geotechnical configurations, and existing infrastructure deterioration conditions as well as differentiating before and after conditions of certain objects through a superimposing technique.

\section{Data superimposition comparison}

This study utilized the data superimposition method to identify the differences of the after-construction results, i.e., the as-built, from the as-planned design of the facility. Comparative analysis was performed on the five regions of the facility as shown in Figure 7 (i.e., location 1, 2, 3, 4, and 5) with respect to whether the curvatures of the panels in each region are accurately maintained. Figure 8 shows the three-dimensional comparison of the facility mass. Red-colored areas indicate that the panels in the areas were overall produced and fabricated as planned. On the contrary, the areas in white color include the panels of which shapes and curvatures were more or less different from as-planned.

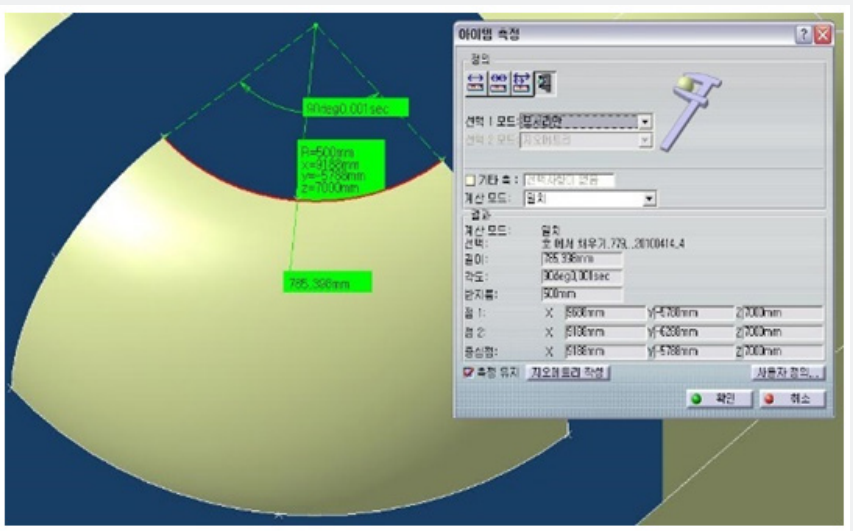

(A)

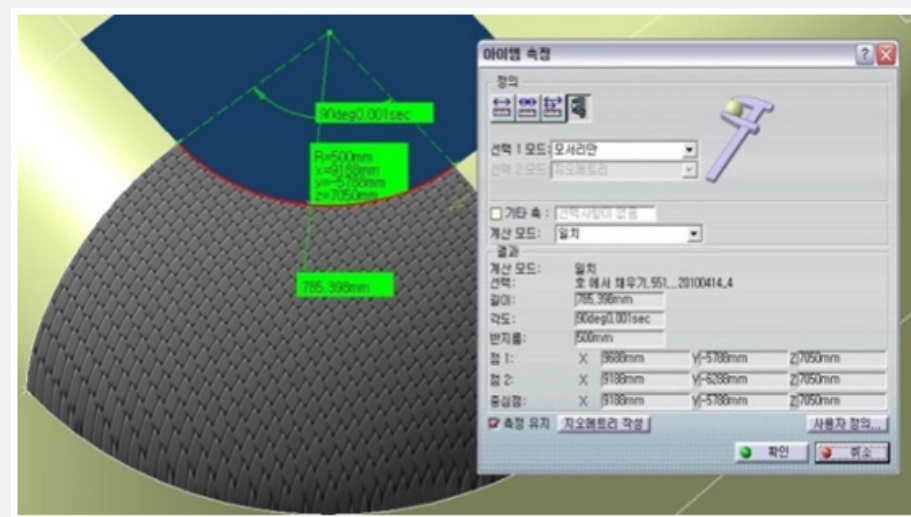

(B)

Figure 7: Numerical Measurement of Difference.

(a) As-Planned Data at Point $X$.

(b) As-Built Data at Point X. 


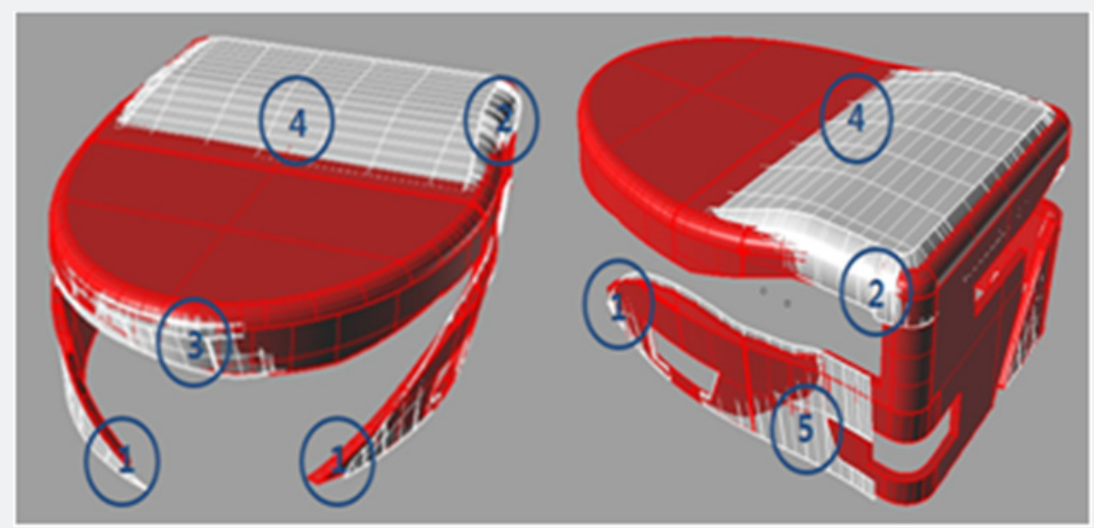

Figure 8: As-planned and As-built Facility Mass Comparison.

Table 1 summarizes the differences. Discrepant contents in region 1, 4, 5 take place in the single curvature panels while regions 2 and 3 involve double curvature panels and their unlike contents show different features from regions 1, 4, and 5. Based

Table 1: Defects at the various regions of the building. on the superimposition comparison, it can be inferred that as the curvature gets more complex and bigger, the panel changes during forming and fabrication become bigger.

\begin{tabular}{|c|c|c|}
\hline S.No & Difference Contents & Panel Types Related \\
\hline \multirow{2}{*}{1} & Panel Finishing Location & \multirow{2}{*}{ Single Curvature Panels } \\
\hline & Panel Length & \\
\hline \multirow{3}{*}{2} & Panel Connection Position & \multirow{3}{*}{ Double Curvature Panels } \\
\hline & Panel Size & \\
\hline & Panel Curvature Size \&Shape & \\
\hline \multirow{3}{*}{3} & Panel Curvature Starting Point & \multirow{3}{*}{ Double Curvature Panels } \\
\hline & Panel Size & \\
\hline & Panel Curvature Size\& Shape & \\
\hline 4 & Panel Slope Degree & Single Curvature Panels \\
\hline \multirow{2}{*}{5} & Panel Size & \multirow{2}{*}{ Single Curvature Panels } \\
\hline & Panel Connection Position & \\
\hline
\end{tabular}

\section{Data quantitative comparison}

In order to numerically measure the difference between the as-built and the as-planned products, spreadsheet application was performed along with one panel in region 2 . Figure 7 a \& $7 \mathrm{~b}$ presents the measurement results delivering the $\mathrm{X}, \mathrm{Y}$, and $\mathrm{Z}$-coordinates of a specific point on the as-planned panel $(\mathrm{X}, \mathrm{Y}, \mathrm{Z}$ $=9188,5788,7000)$ and the as-built panel $(X, Y, Z=9188,5788$, 7050).

The existence of a $50 \mathrm{~mm}$ difference at $\mathrm{Z}$ coordinate means that the designated panel at region 2 was constructed $50 \mathrm{~mm}$ higher than initially planned, and the panels that are next to the panel also would be twisted from their original coordinates because of this error. This twisting may cause lifting of panels and panel joints, water leakages, and falling off finish materials when fixing the panels to the main or sub frames [15].

\section{Mock-Up Fabrication}

The main objective of this research is to measure as-built quality of the free-form panels formed and fabricated with the cold bending method. While the best practice to meet this research objective is to perform empirical tests using diverse panels through case studies, there are very few free-form buildings available to test for cold bending and furthermore, the contractors of the buildings do not want to use their facilities as case study objects where 3D laser scanning technology is used to reveal the quality of built outputs.

The authors instead produced mock-up panels by cold bending. This will help to make the findings from Haewoojae more reliable and generally viable. The mock-up panels were made with aluminum and GFRC (Glass Fiber Reinforced Concrete) which were the most commonly used in free-form buildings in Korea. A total of 8 panels including one flat panel, two single curvature panels (one with curvature more than $200 \mathrm{~mm}$ and the other less), and one double curvature panel with $800 \mathrm{~mm} \times 600 \mathrm{~mm}$ size each other were produced from each material. During mock-up panel production, 2 experts of each material were in attendance and advised on the physical properties of the materials, fabrication, equipment usage, and surface machining methods. 


\section{Civil Engineering Research Journal}

\section{Mock-up production process}

Constructing free-form façade panels with cold bending technique requires 2D fabrication drawings. Figure 9 shows the 2D drawings of the double curvature panel to be used for producing mock-up panels for this study, which were extracted from the 3D BIM modeling data. The single curvature surface has one curvature value so that the $2 \mathrm{D}$ drawings can be easily defined from the 3D BIM data. But as for the double curvature surface, points and lines in the drawings should be approximately drawn with a certain range of error and close attention needs to be paid during the actual production of the panels so as to keep the error within that range.
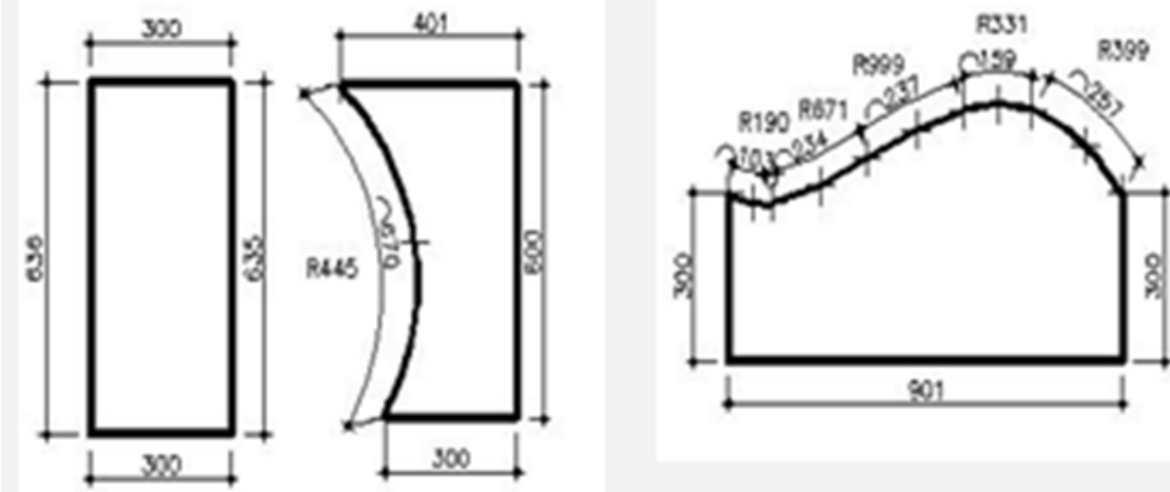

Figure 9: 2D Panel Assembly Drawing for Mock-up.

\section{Aluminum mock-up panel production.}

Carving, casting to pour, and solidify material are not appropriate for fabricating metal panels [3]. Cutting, roller bending, and pressing are methods generally used to fabricate curved metal surfaces. In the case of roller bending, the radius of a curved surface must be more than $200-300 \mathrm{~mm}$. If the radius is less than $200 \mathrm{~mm}$, then press bending is used.

The flat and single curvature mock-up aluminum panels were produced by roller bending and press bending techniques. During roller bending, the aluminum sheet was placed between a surface controlling roller and a fixed roller set with the desired curvature. A press bending machine pushes and folds a sheet metal panel. Both roller bending and press bending are typically used to produce a uniformly bent shape, but are not suitable for creating a bent shape with varying curvatures or double curvature panels.

When producing the flat and single curvature panels, the sub-frames were in the first place cut with a CNC machine and the four sides of a panel were assembled using bolts before fixing a sheet on top. Figure 10 shows the single curvature panel fabrication process.
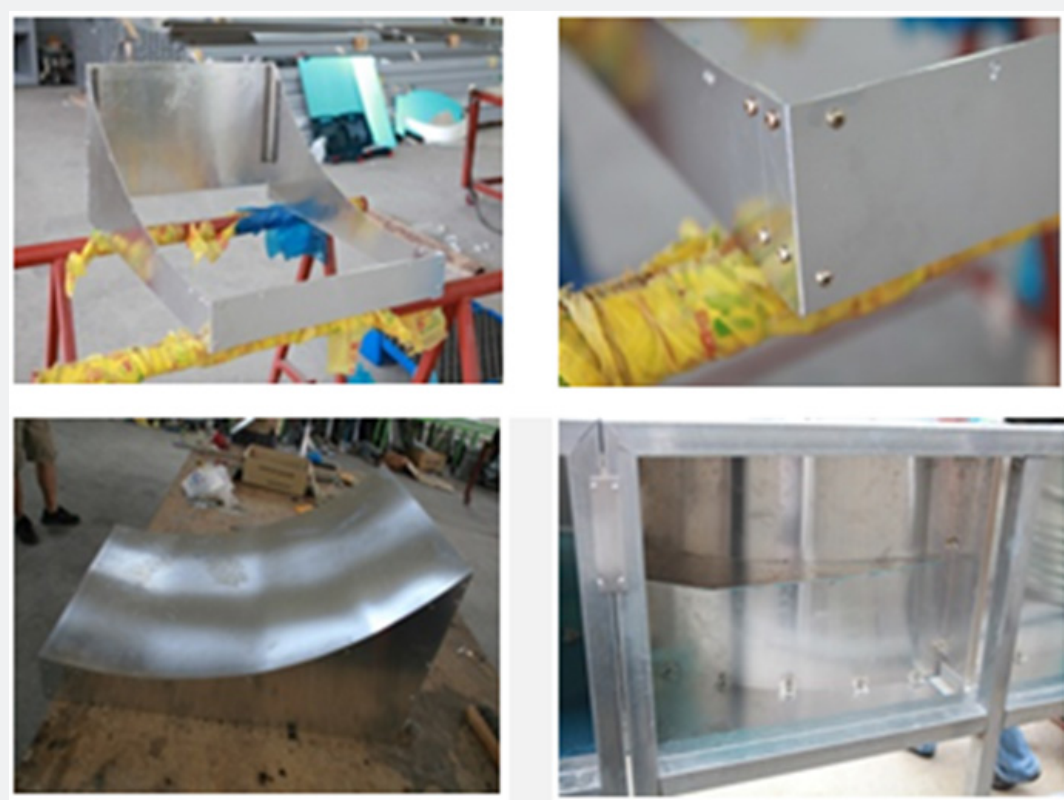

Figure 10: Single curvature panel fabrication process (From top left, clockwise). 


\section{Civil Engineering Research Journal}

Unlike the flat or single curvature panel, the double curvature panel can be easily flattened by tensile force so that an intermediate sub-frame was added in the mock-up production. Discussing with the experts, it was found that the double curved panel with concave curvature can be fastened to the mainframe by its edge with small possibility of deformation, but in case of the convex curvature, the sub-frame was definitely necessary to maintain its curved shape.

The authors tried to form and fabricate the mock-up aluminum double curvature panel with the procedure shown in Figure 10, but since aluminum could not bear the bending stress, it got destroyed during fabrication. The panel was so that formed with the combination of press bending with hammering depending on the panel-forming workers' proficiency.

\section{GFRC mock-up panel production}

In manufacturing GFRC panels, formwork fabrication is the most important activity. Since it is not possible to use a structured formwork for free-form façades such as Euro form, a separate formwork should be produced and in the first place molds must be made for producing the formwork. Molds can either be made from wood or Styrofoam. Styrofoam was used in this study. The mold was produced by entering its 3D geometric information into a CNC machine, which automatically produced the mold as shown in Figure 11a.
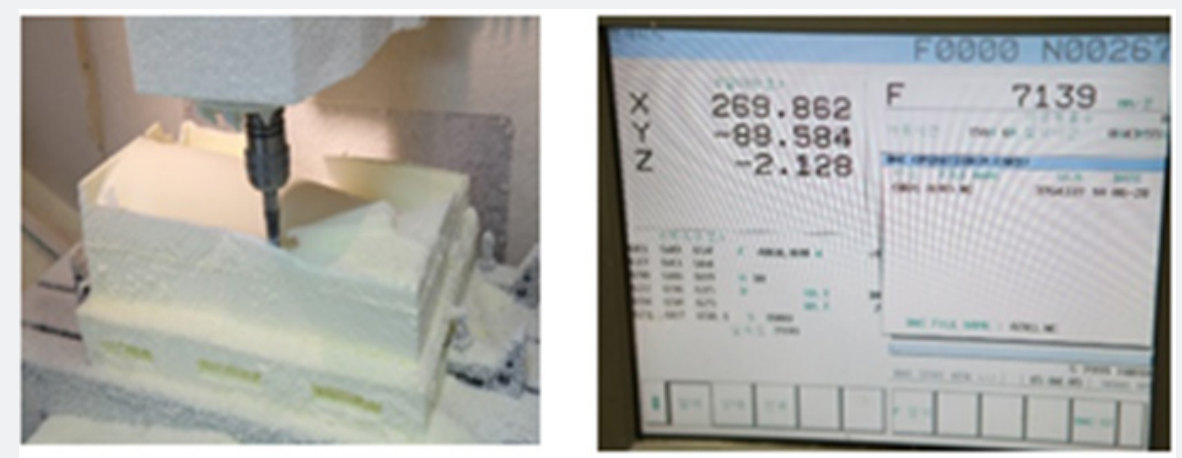

(A)

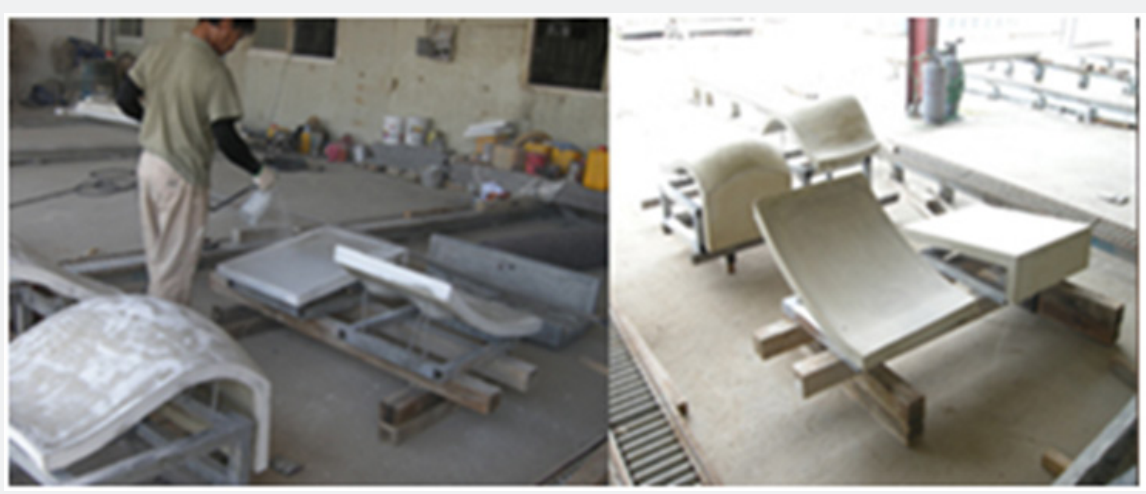

(B)

Figure 11: GFRC Panel Production Process.

Having manufactured the mold, the formwork for making GFRC panels was then produced by pouring concrete into the mold. GFRC materials were then mixed and poured into the formwork, steam cured for 8-9 hours and then the formwork was taken off from the GFRC panel (See left picture of Figure 11b). The panel was painted with 2 coats of the desired colors as the final step in the manufacturing of the GFRC panels (Figure 11b).

\section{Mock-up data analysis}

The superimposition method based on 3D laser scanning technique was used again to compare the as-manufactured with as-designed mock-up panels. Figure 12 shows as-designed mockup data while Figure 13 as-manufactured ones respectively. The upper parts of the panel pictures and table data in Figure 12 are about 4 aluminum panels and the lower parts 4 GFRC panels. The first panel shapes in both the upper and lower parts are flat panels, the second and the forth single curvature panels, and the third double curvature panel (i.e., (C) on the double curvature aluminum panel, (C-1) on the double curvature GFRC panel). Figure 13 delivers the same formation of data layout as Figure 12 regarding as-manufactured panel data.

Reviewing the X, Y, and Z coordinates in Figure 12 \&13, it is understandable that the aluminum mock-up panels demonstrate bigger discrepancy than the GFRC panels. This tendency can be explained in conjunction with the material features, so to speak, the spring-back of aluminum and flexible workability of concrete. 


\section{Civil Engineering Research Journal}

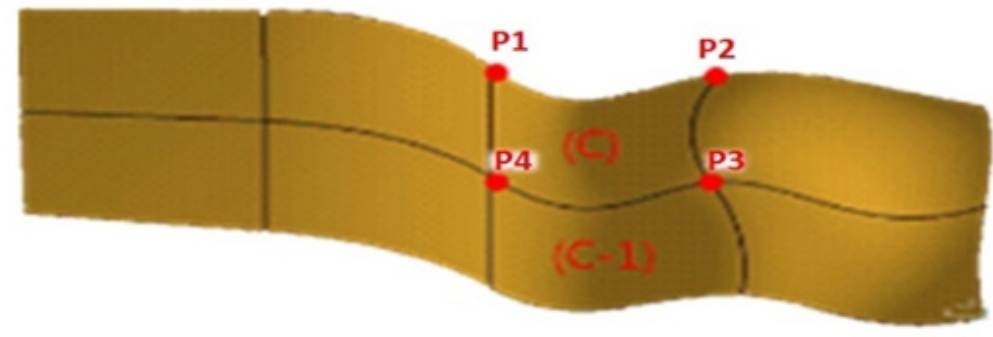

Figure 12: As-designed Mock-up Panel Data.

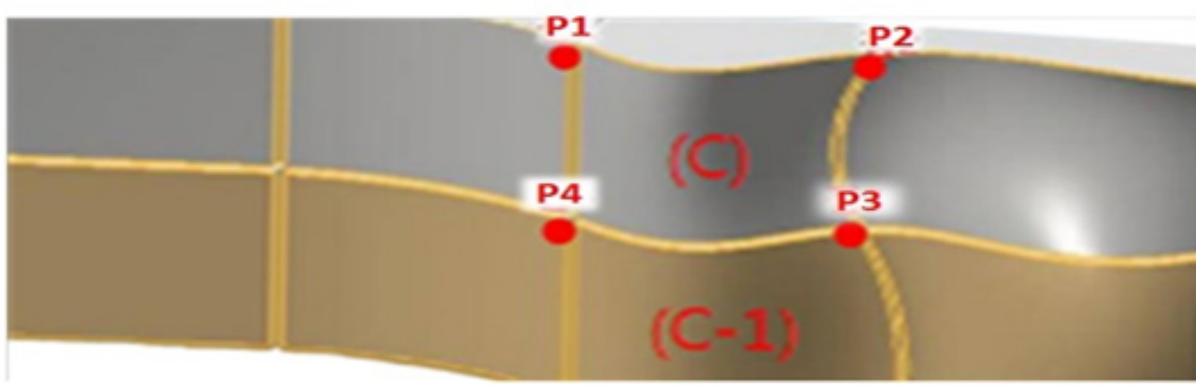

Figure 13: As-manufactured Mock-up Panel.

Table 2 summarizes the discrepancy of the as-designed and as-manufactured coordinate points of the double curvature aluminum mock-up panel. The length difference between point

between point 1 and point 3 was $3 \mathrm{~cm}$ [2]. This discrepancy was found to exceed the aluminum production allowance provided 1 and point 2 was measured to be $3.57 \mathrm{~cm} \mathrm{[1]} \mathrm{while} \mathrm{the} \mathrm{length}$ by the Korean Industrial Standard in Table 3.

Table 2: Coordinate Points of Aluminum Mock-up Panel C

\begin{tabular}{|c|c|c|c|}
\hline & $\mathbf{x}$ & $\mathbf{Y}$ & $\mathbf{Z}$ \\
\hline & $\mathbf{m m}$ & $\mathbf{m m}$ & Mm \\
\hline Surface C & \multicolumn{3}{|c|}{ Aluminum Panel } \\
\hline C point1 & 1580 & 100 & 1200 \\
\hline C point2 & 830 & 0 & 1200 \\
\hline C point 3 & 880 & 0 & 600 \\
\hline C point4 & 1580 & 100 & 600 \\
\hline Surface C-1 & \multicolumn{3}{|c|}{ GFRC Panel } \\
\hline C-1 point1 & 1580 & 100 & 580 \\
\hline C-1 point 2 & 880 & 0 & 580 \\
\hline C-1 point 3 & 780 & 0 & -20 \\
\hline C-1 point4 & 1580 & 100 & -20 \\
\hline
\end{tabular}

\begin{tabular}{|c|c|c|c|}
\hline & X & Y & Z \\
\cline { 2 - 4 } & mm & mm & Aluminum Panel \\
\hline Surface C & \multicolumn{2}{|c|}{ Mm } \\
\hline C point1 & 1593 & 103 & 1205 \\
\hline C point2 & 880 & -3 & 1197 \\
\hline C point3 & 863 & -5 & 595 \\
\hline C point4 & 1590 & 102 & 592 \\
\hline
\end{tabular}




\section{Civil Engineering Research Journal}

\begin{tabular}{|c|c|c|c|}
\hline Surface C-1 & \multicolumn{3}{|c|}{ GFRC Panel } \\
\hline C-1 point1 & 1584 & 101 & 575 \\
\hline C-1 point2 & 876 & 0 & 581 \\
\hline C-1 point3 & 781 & 0 & -17 \\
\hline C-1 point4 & 1577 & 97 & -15 \\
\hline
\end{tabular}

\begin{tabular}{|c|c|c|c|}
\hline Location & X Direction Discrepancy & Y Direction Discrepancy & Z Direction Discrepancy \\
\hline Point 1 & $13 \mathrm{~mm}$ & $3 \mathrm{~mm}$ & $5 \mathrm{~mm}$ \\
\hline Point 2 & $50 \mathrm{~mm}$ & $-3 \mathrm{~mm}$ & $-3 \mathrm{~mm}$ \\
\hline Point 3 & $-17 \mathrm{~mm}$ & $-5 \mathrm{~mm}$ & $-5 \mathrm{~mm}$ \\
\hline Point 4 & $10 \mathrm{~mm}$ & $2 \mathrm{~mm}$ & $-8 \mathrm{~mm}$ \\
\hline
\end{tabular}

Table 3: Korean Industry Standard of Aluminum Production Allowance.

\begin{tabular}{|c|c|c|c|}
\hline Dimension Range (mm) & Length, Width (mm) & Diagonal (mm) & Bending \\
\hline W, L $<1500$ & \pm 1.5 & \pm 2.0 & $1 \mathrm{~mm}$ per $1 \mathrm{~m}$ \\
\hline
\end{tabular}

It would therefore pose problems like twisting at the time of fixing a number of aluminum panels side by side on the mainframes and sub-frames as designed. This twisting could also lead to other defects in the long run, such as bulging, water leakages, and failure of some finishing materials.

\section{Summary \& Limit}

Through a case study and a mock-up panel fabrication test, the study demonstrated that cold bending of metal sheets with a roller or a press seems to have difficulty in meeting the asplanned shapes of double curvature panels. Although there could be controversy regarding the worker's level of expertise in handling the panels, considering the fact that the workers in Haewoojae and the mock-up panel test have been involved in the architectural façade fabrication field for more than 10 years and successful in a number of projects, using a cold bending technique for forming double curvature panels needs careful technical consideration for securing quality free-form products.

In parallel with proceeding the mock-up test, interview was conducted with the 4 experts who consulted for the mock-up test to get an advice on their experience. Referring to the EMP as an example, they pointed out that cold bending is not suitable for double curvature panels. While the EMP demonstrated the use of cold bending in its double curvature panels, only small pieces of sheet metal were used for double curvatures and for mild curvature panels, large pieces of sheet metal were utilized to minimize the breaks among the panels. Despite this design consideration to prevent discontinuity of curvature due to the breaks from occurring, the breaks made during cold bending are easily observed.

It was the experts that commented in case where only cold bending technique is available for free-form façade fabrication, it is better to design a façade surface having shapes and curvatures that can be divided into smoothly bent single curvature panels rather than using complex curved surfaces. As well, it was discussed that providing a certain range of tolerance in panel joints to the extent where the visual continuity of curvature among panels is maintained is necessary to obtain aesthetic free-form products.

While the findings from this study are beneficial to designers, contractors, and project owners for securing quality free-form products, there is certain limitation to bring out advanced inferences for future application due to the limit of case study materials. As more free-form projects are built in the future, the authors will perform advanced research to deliver more reliable findings.

\section{Conclusion}

Free-form buildings are known to be difficult to construct due to their unique shapes and non-conformity to conventional building techniques. The façade design and installation is considered to be the most difficult stage in free-form construction. This is because the facades require cutting edge accuracy in the design, panelization, optimization, fabrication and installation of façade panels in order to be delivered as intended by the designer. Therefore ultimate care should be taken during each of those stages as any mistake could lead to dire consequences for the project. The choice of material and method of production of the panels has always been a point of concern for the free-form design and construction teams. Choice of an unsuitable material or fabrication method could lead to escalation of costs and problems during and after installation of the façade panels.

This study focused on cold bending method of free-form panel manufacturing and installation. Three free-form buildings namely Haewoojae toilet museum and J museum in Korea, and Experience Music Project in the United States, whose panels were fabricated by cold bending were reviewed. The as-built BIM 


\section{Civil Engineering Research Journal}

drawings of Haewoojae were obtained by 3D laser scanning and compared with the as-planned drawings by the superimposition technique. The results of the comparison showed that the installed facade panel data deviated from the originally planned design data.

In order to make the findings more reliable, mock-up panels made of aluminum and GFRC were designed and fabricated by cold bending. The panels of each material were of three curvatures types namely flat, single curved and double curved panels. The flat and single curved panels' data was found to match. However, the data for the double curved panels for both aluminum and GFRC was found to have a certain deviation which exceeded the Korean standard allowance limits. This would pose problems like twisting at the time of fixing several aluminum panels side by side on the mainframes and sub frames as designed for the free-form structure. This twisting could also lead to other defects in the long run, among others; bulging, leakages, falling off of some components.

Cold bending was therefore found to be suitable for manufacture of flat and single curved metal panels. For the case of double curved panels, cold bending was found to be applicable to a certain limit of curvature of the panel depending on the expertise of the manufacturer.

\section{Funding}

This research was supported by a grant (15-AUDP-C067817-03) from the Architecture \& Urban Development Research Program funded by the Ministry of Land, Infrastructure and Transport of the Korean government.

\section{References}

1. Eekhout M, Barbara G, Walter L, et al. (2015) Free Form Technology from Delft. Research in Architectural Engineering, Vol 14.

2. Kim SW (2009) Classification and Optimization of Irregular Shaped Building Panels by Fabrication Methods: Focused on Dondaemun
Design Plaza and Park. A Master of Science Thesis, Yonsei University, Korea, pp. 27-33.

3. Lee G, Kim SW (2012) Case study of mass customization of double curved metal façade panels using a new hybrid sheet metal processing Technique. Journal of construction Engineering and Management, ASCE 138(11): 1322-1330.

4. Piegl LA, Tiller W (2002) Biarc approximation of NURBS curves Computer-Aided Design 34(11): 807-814.

5. Park HK, Ock JH (2015) Developing the Preliminary Cost Estimate for the Free-Form Building Façade in Conjunction with the Panel Optimization Process. KSCE Journal of Civil Engineering 19(5): 12141223.

6. Shelden DR (2002) Digital surface representation and the constructability of Gehry's architecture. Doctoral thesis, Massachusetts institute of Technology, Boston, USA.

7. Suchy I (1998) Bending and Forming Operations. Handbook of Die Design, Second Edition, McGraw-Hill publishers, New York.

8. Richard MC (2016) Physical Ductility of the Elements.

9. Jayme DB (2016) XTU architects: Jeongok prehistory museum." Designboom architecture design art technology shop.

10. Wikiarquitectura (2013) Experience Music Project.

11. Saranguimoim (2016) Suwon Haewoojae (Toilet museum).

12. Su YY, Hashash YMA, Liu LY (2006) Integration of construction asbuilt data via laser scanning with geotechnical monitoring of urban excavation. Journal of construction Engineering and management, ASCE 132(12): 1234-1241

13. Shin NJ, Huang ST (2006) 3D Scan Information Management System for Construction Management. Journal of construction Engineering and management 132(2): 134-142.

14. Park JS, Pyeon MU, Jo JH, Lee GH (2011) Case Study of Civil-BIM \& 3D Geographical Information. Korean Journal of Land Surveying 29(6): 569-576.

15. Ock JH (2010) New technology research and development support Report. Seoul National University of Science and Technology, Seoul, Korea.

\section{Your next submission with Juniper Publishers} will reach you the below assets

- Quality Editorial service

- Swift Peer Review

- Reprints availability

- E-prints Service

- Manuscript Podcast for convenient understanding

- Global attainment for your research

- Manuscript accessibility in different formats

( Pdf, E-pub, Full Text, Audio)

- Unceasing customer service

Track the below URL for one-step submission https://juniperpublishers.com/online-submission.php 